\title{
Reflective Blogging: Education in a Social Constructivist Environment - A Case Study
}

\author{
Rashika Sharma and Sylila Monteiro
}

\begin{abstract}
The emergence of e-learning is an educational trend that aligns appropriately with contemporary technological change. The $21^{\text {st }}$ century learner expects self-directed facilitation characterised by various communication and social networking platforms. These collaborative networks offer interactive learning environments that cater to individual learning preferences. Accessibility to a wide range of personal and professional communities simultaneously broadens the scope of the educational as well as the personal experience for the learner.

E-learning settings continue to enrich the learning experiences of today's digital natives. Advanced e-learning technologies, such as Web 2.0, provide a foundation for dynamic interaction between learner and teacher. These learning technologies provide the "basis for enhancing teaching and learning in virtually any discipline, providing an environment that stimulates reflection, critique, collaboration, and user generated content-i.e. a social constructivist environment." The dynamic interactive online spaces created by podcasts, vodcasts, wikis, instant messengers (IM), social bookmarks and weblogs, build a community of practice open to collaborative discussion which generates reflection and critical thinking, ultimately creating discerning global citizens.

The concept of reflective practice is the cultivation of the capability to reflect in action whilst doing something, and to reflect on action -after it has been done. This reflective writing pedagogy creates an alternative to the traditional education approach of theory first and then practice. In modern day terms it may be assumed that blended learning extends this reflective writing pedagogy using Web 2.0 technologies as an interface for reflection.

Weblogs were introduced as a platform for reflection in an Applied Technology undergraduate course. This case study demonstrates the student perceptions of weblogs, its application and challenges as well as its validity as a reflective medium. The themes that emerged substantiate that weblogs promote collaboration and track learning progression of individual students. However the level of familiarity with the technology and ICT skills impacted on performance. Social constructivism evolved through the intersubjectivity of the community of practice and supported collaborative learning.
\end{abstract}

Index Terms-E-learning, weblogs, social constructivism, virtual community of practice (vcop).

\section{INTRODUCTION}

Learning is a social process that occurs within an individual through passive development of behaviours that are shaped by external forces [1]. Social constructivists

Manuscript received February 1, 2012; revised March 9, 2012.

R. Sharma and S. Monteiro are with Unitec Institute of Technology, Auckland, New Zealand (e-mail: rsharma@unitec.ac.nz; smonteir@unitec.ac.nz). therefore believe that reality, knowledge and learning are constructed socially and culturally through human activity. Meaning is created through individual interactions and with the environment students live in.

Contemporary learning and teaching strategies are designed to reflect the new world e-learning environment and to embrace technologies that continue to evolve and transform education. E-learning is the core response to these revised learning and teaching strategies. E-learning facilitates the social constructivist theory as it provides a platform for establishing collaborative learning. E-learning is defined as formal and non-formal education that uses electronic delivery methods such as internet-based learning delivery packages, CD-ROM, online video conferencing, websites or email to manage the relationship between teacher and learners [2]. Technological change continues to modify the role of learners and educators. The current cyber generation expects today's education system to present a technologically diverse learning environment.

The web is a dynamic interactive space, a tool that promotes social networking and assists in establishing communities of practice where knowledge, reality and learning are disseminated. Emerging uses of Web 2.0 technologies to support social networking and collaborative learning are increasingly important in shaping the new learning environment. Web applications supported by Web 2.0 permit interaction and collaboration on the World Wide Web. Participatory dialogue ensues and creates user generated content in a virtual community. Web 2.0 tools such as social networking sites, weblogs, wikis, Podcasts, vodcasts, instant messengers (IM), social bookmarks have the potential to meet the needs of the $21^{\text {st }}$ century learner generation, who seek greater autonomy as well as collaborative networks and interactive learning styles. Learning activity changes as technology has reorganized how we live, how we communicate and how we learn [3].

Reflective practice is vital to cultivating cognitive skills and developing a variety of other essential generic skills. Reflection is learning to learn. Reflective practice is meta-management of concentration, comprehension and affect through which a learner considers the variables in the learning process and looks at alternative pathways and solutions [4]. In its simplest definition, reflection can be seen as "consciously thinking about and analysing what one has done (or is doing)" [5]. This is an everyday occurrence. In reflective writing structured approaches that exist in learning situations enable students to understand their own learning process [4]. In addition, reflective learning encourages deeper learning and understanding, and offers a relevant framework for development of professionals who will be 
lifelong learners, committed to continuous improvement of their practice [6]. Reflection in terms of learning "is a generic term for those intellectual and affective activities in which individuals engage to explore their experiences in order to lead to new understandings and appreciations" p.7 [7]. For digital natives new media technologies are more appropriate than paper based reflective logs because they already participate on a global level. Blogging is the new reflective platform where dynamic collaboration becomes viable and enhances critical thinking. Web 2.0 increases participation and confirms to students that education is a constantly evolving entity. By allowing students to use the technology tools of Web 2.0, teachers are presenting students with the opportunity to learn for themselves and share their learning with their peers locally as well as globally.

\section{The CASE Study}

Weblogs are a resource primarily meant for communication but the information can be organised in such a manner that makes weblogs an ideal platform for a reflective journal. Students can individually express and reflect on their thoughts, their experiences, at the same time sharing reflections with peers and receiving teacher feedback. Weblogs were introduced as a medium for reflective writing for a course in an Applied Technology degree in New Zealand. The course entitled "Communication, Problem Solving and Health \& Safety" is a mandatory first semester generic course offered to students specialising in automotive technology, marine technology or electro technology. Part of the assessment for the course requires students to maintain a weekly reflective journal as evidence of their individual progression of learning. The reflective journal contributes 10 per cent towards the students overall grade for the course. Prior to 2010 students were expected to maintain a paper based reflective journal. However with the growing emphasis on e-learning, weblogs were introduced in the course in Semester one of 2011. To examine the value of this intervention it was essential to gauge students' perception of blogging as a reflective tool. This paper presents research findings and student responses.

\section{Methodology \& SAMPle Description}

A qualitative approach was chosen for this research with questionnaires used as the prime source for data collection. Reference [8] indicates that "qualitative, less structured, word based and open-ended questionnaires may be more appropriate as they can capture the specificity of a particular situation" (p. 247-248). A semi-structured questionnaire was designed with both closed and open qualitative questions. Data collected not only generated numerical data for comparison purposes but also provided an insightful spectrum of student opinions.

\section{Data AnALysis}

The student sample consisted of sixty five, Semester One 2011 undergraduates. A total of fifty six students participated in the research generating an 86 per cent response rate. The participants were mainly males with only 6 per cent females.

Reflective writing was a new learning experience for 64 per cent of participants' whereas 36 per cent were familiar with this assessment tool. However blogging was completely new for 61 per cent of the cohort indicating that 3 per cent out of the 64 per cent who had never kept reflective journals had participated in personal blogging prior to embarking in the course. Only 39 per cent of the participants had prior experience with weblogs. Student feedback on weblogs indicates that 82 per cent viewed it positively. The majority of the students evaluated it as an average reflective tool as illustrated in Fig. 1.

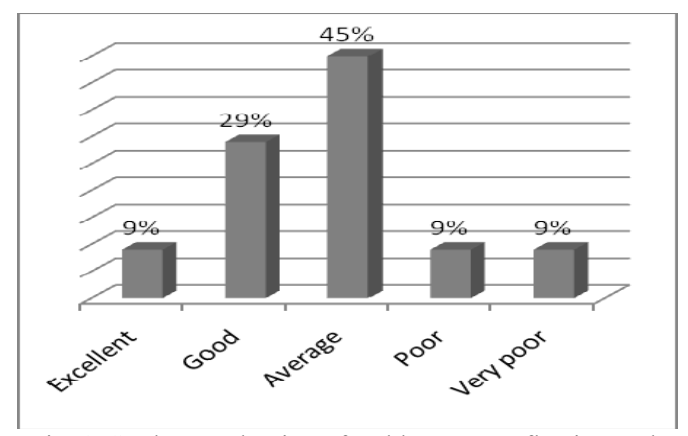

Fig. 1. Student evaluation of weblogs as a reflective tool.

The literature reviewed indicates several similar trends to these results. Reference [9] stated that communications, arts or education majors found blogs more useful than science or math majors who suggested that they could only use blogs to debate theories and ethical questions. This confirmed that applied technology students who preferred experiential learning - learning by doing - were inclined to consider blogging negatively.

Reference [10] also corroborated that some students felt discomfort in expressing feelings and opinions in public forums. They further stated that analysis of patterns of interaction showed that blogs were not well used as a communication tool for interactions with student peers but were helpful for communication with the tutor. This reluctance towards blogging could adversely affect student ratings of blogs as a learning tool. The creation of a safe, comfortable classroom atmosphere as well as a positive teacher- student relationship would be conducive to blogging.

Through this research it was evident that the theory does not necessarily fully support the practicalities of blogging. The researchers found the following impediments:

- Most importantly for weblogs to function effectively computer accessibility is the vital feature. In addition to PC, laptops, iphones, ipads, tablets and wifi are recommended to facilitate e-learning through blogging.

- Some technically oriented students are impatient with blogs therefore it is recommended that future researchers consider additional support for these students.

- Some mature students may not be social network savvy to engage effectively in blogging. Such students will benefit through peer mentoring.

The above three aspects can be of significance in future research. 


\section{DISCUSSION}

Three major themes emerged from this research on students' perception of weblogs as a medium for reflective writing.

\section{A. Group Interaction \& Communication}

Collaboration and group interaction was highlighted by students as the most beneficial characteristic of weblogs. Students commented that "It's good to best to stay connected with your friends and keep updating your reflective writing" and "allow tutors to see interaction within the group." The interaction between students and their peers and between tutors and students created a positive learning environment that encouraged participation in blogs. Reference [11] stated that a suite of creative, critical, communication and collaboration skills can be addressed successfully by using blogs. Blogs can help students improve the quality of their writing through a combination of peer and lecturer feedback, and in so doing develop critiquing skills to give feedback [12]. This is further elaborated by a student commenting that "as a learning tool blogs help to generate new ideas and reflect on the mistakes made, this will help to get 'it' right or at least make improvements on the next similar project".

Researchers as mentioned earlier, have confirmed that blogs allow open communication and interaction between teacher, student and peers forming collaborative communities of practice. Student comments that weblogs are "very good to share information" and "sharing info with other students on-line" authenticate parallels with literature that weblogs create a culture of collaboration which is essential for real world learning. Weblogs are seen as excellent in recording individual's progress, accomplishments and reflections [13].

Constructivist pedagogy theorised by Kant and Hegel is demonstrated through the practice of online collaborative learning. Constructivism through blogs or groups of blogs creates a community of learners. Reference [14] confirms that blogging is about creating learning communities communities of practice.

\section{B. Familiarity with Technology \& Internet Connectivity}

Student engagement and familiarity with computer technology together with the challenges presented by Web 2.0 influenced the frequency of blogging. Many mature students commented that 'the whole thing (blogging) is difficult for me not really knowing even basic computer skills' and another student stated that 'I think I'm getting old and I mostly forget how to create a blog. However for the first time I got through but in the middle of the semester I couldn't get through.' These comments contradicts [15] statement that blog's "underdetermined" design, where the system is engaging, yet intuitive and easy to learn makes it equitable for many age groups and both genders. However the results of this study align positively with [16] who mention that the basic mechanics of blogging was a challenge for students in their research as well. Some preferred traditional pen and paper environment compared to the online learning. Those who were hesitant to engage in blogs were mature students diffident with ICT. This is a consequence of the digital divide. However some students, the digital natives, were more optimistic towards using blogs and were keen to take up the challenge though it was a new learning environment for them. 'I've never done it before so in terms of learning a new skill expands my knowledge in dealing with computers'. Approximately 73 per cent students were either confident or very confident in the new e-learning environment as evident in Figure 2.

\section{Learning Progression}

Learning is a continuous process creating change - change in the ways in which people 'understand, or experience, or conceptualize the world around them' p.4 [17]. Static learning is acquiring information. Static learning creates a repository of knowledge through which facts, skills, experiences and methods are not merely retained but can be recalled and applied in future situations.

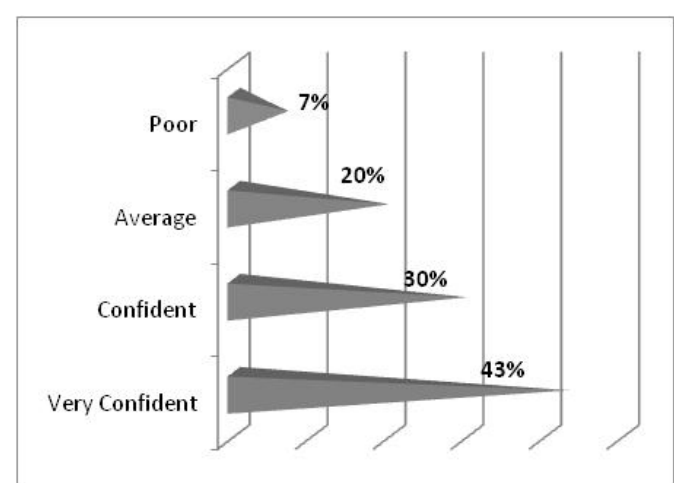

Fig. 2. Student's reflection on their familiarity with the on-line environment.

Learning entails abstracting meaning, interpreting knowledge and associating subject matter to each other and to the real world. Learning is complex as the individual interprets and understands reality in a variety of contexts. Reference [17] stated that learning involves comprehending the world by reinterpreting knowledge.

In the real world choices have to be made, some simple others multifarious. Reflective practice naturally comes into play in problem solving and decision making as it is an innate characteristic for an individual to rationalize. This process of reflection unconscious or implicit as it maybe or conscious or formal as the individual chooses affects the learning process and new knowledge is generated. Student feedback corroborated that reflection is a tool that facilitates learning progression. Their comments on their reflective blogs are as follows:

They [blogs] are effective for looking back identifying problems and solutions used.

As the learning tool blogs help to generate new ideas and reflect on the mistakes made, this will help you to get 'it' right or at least make improvements on the next similar project.

It keeps you active and makes you reflect on your previous work which helps you learn to remember the ideas you came up with.

The comments above are evidence of self evaluation and self critiquing effecting change and furthering learning progression through student self awareness. Reflective thinking and self-perception becomes a continuous, conscious or unconscious evaluative process, a combination of reflection-in-action and reflection-on- action. Critical deep 
reflection gives insightful self-analysis bringing about attitudinal change and progression in learning. Skills in communication, critical thinking, self-learning, self- and social awareness, empathy, and sensitivity to cultural differences are developed. In higher education, students find peer evaluation "less anxiety-provoking" p. 72 [18] as students enjoy the sense of ownership and direct involvement in judging the quality of student achievements [19]. On going and immediate teacher feedback is invaluable from the formative view point. Reference [20] also indicates that when feedback and reflection are integrated in the form of reflective conversations between teachers and students, both teachers and students could benefit from the reflective practice. Thus self- evaluation, peer evaluation and teacher feedback augment social networking and creates a virtual community of practice (VCOP) lending to social constructivism.

\section{SOCIAL CONSTRUCTIVISM THROUGH VCOP}

The VCOP is a dynamic, 'living curriculum' forum, facilitating learning of all who are involved. The management of knowledge evolves through the collective responsibility of its professional practitioners. A direct relationship occurs between learning and performance with knowledge creation and sharing which is the basis of social constructivism. Thus the VCOP participants are 'prosumers' - stewarding knowledge on a global platform as there are no limitations of formal structures nor geographical boundaries. This intersubjectivity of the VCOP supports collaborative learning. According to Vygotsky constructivism is social interaction that develops cognition and increases the repository of knowledge as learning is a social process and reality evolves through human activity. Web 2.0 tool weblog presents a variety of possibilities for reflection, rapid ongoing feedback and knowledge creation which is social constructivism in action.

\section{CONCLUSION}

Education in today's global blended environment is a creative commons where knowledge construction, application, evaluation and revision occur as an on going process. New knowledge evolves through a combination of reflection and collaboration as 'new kernels of truth' emerge. Web 2.0 is an ideal tool for the e-learning Gen Y digital natives who are prosumers, the social constructivists of knowledge.

\section{REFERENCES}

[1] M. McMahon, "Social Constructivism and the World Wide Web - A Paradigm for Learning," presented at the ASCILITE conference, Perth, Australia, 1997.

[2] Ministry of Education. http://www.educationcounts.govt.nz/publications/series/2531/54560/2

[3] G. Siemens. 2005. A Learning Theory for the Digital Age. Available: http://www.elearnspace.org/Articles/connectivism.htm

[4] S.R. Monteiro, "Reflective Practice - The Laser Striking new chords in communication," presented at the at the combined 15 National Annual Conference of the New Zealand Communication Association Inc. and The Association for Business Communication $4^{\text {th }}$ Asia Pacific Regional Conference, Auckland, December 10-12, 2003.
[5] Learning Development Unit Unitec. 2007. MlearnBlogging. Available: http://ctliwiki.unitec.ac.nz/index.php/MlearnBlogging

[6] K. Henderson, K. Napan and S. Monteriro, "Encouraging reflective learning: An online challenge," presented at the ASCILITE conference, Perth, Australia, 2004.

[7] D. Boud, "What is reflection in learning," in Reflection: Turning the experience into learning, D. Boud, R. Keogh, \& D. Walker, Ed. London: Kogan Page, 1985.

[8] L. Cohen, L. Manion and K. Morrison, Research Methods in Education. $6^{\text {th }}$ edition. Great Britain: TJ International Ltd, 2007.

[9] S. Kumar. 2010. Undergraduate perceptions of the usefulness of Web 2.0 in Higher Education: Survey Development. Available: http://plaza.ufl.edu/swapnak/ecel09Kumar.pdf.

[10] K. K. Chan and J. Ridgway. 2006. Students' perception of using blogs as a tool for reflection and communication. Available: www.dur.ac.uk/resources/smart.centre/.../ALT-CEdinburghCHAN.do

[11] P. Duffy and A. Bruns, "The use of wikis , blogs and RSS in education : a conversation of possibilities," in Proc. Online Learning and Teaching Conference, Brisbane, 2006, pp 31-38.

[12] J. Moriarty and V. Rajapillai. 2007. Using blogs for peer feedback in a creative writing course-an exploratory study. Available: http://www.english.heacademy.ac.uk/explore/publications/casestudies /technology/ blogs_fedback.php

[13] M. Weller, C. Pegler and R. Mason. 2005. Use of innovative technologies on an e-learning course. The Internet and Higher Education. [Online].8, 876-880. Available: http://www.qou.edu/arabic/researchProgram/e-learningResearchs/use OfInnovative.pdf

[14] K. Glogowski. 2005. Tools Interiorized. Available: http://www.teachandlearn.ca/blog/2005/12/07/tools-interiorized/

[15] J. Cassell, We Have These Rules Inside: The Effects of Exercising Voice in a Children's Online Forum. Children in the Digital Age: Influences of Electronic Media on Development; Westport: Conn-Praeger, 2002.

[16] T. Hourigan and L. Murray, "Using blogs to help language students to develop reflective learning strategies: Towards a pedagogical framework," Australasian Journal of Educational Technology, vol. 26, no. 2, pp. 209-225, 2012.

[17] P. Ramsden, Learning to Teach in Higher Education, London: Routledge, 1992.

[18] K. Topping, "Self and peer assessment in school and university: Reliability, validity and utility," in Optimising new modes of assessment: In search of qualities and standards, M. Segers, F. Dochy \& E. Casacallar, Ed. London: Kluwer Academic Publishers, 2003, pp. 55-87.

[19] A.M. O’Donnell and K.J. Topping, "Peer assessing peers: Possibilities and problems," in Peer assisted learning, K.J. Topping \& S.W. Ehly, Ed. Mahwah, NJ: Lawrence Erlbaum, 1998, pp. 255-278.

[20] C. Brandt, "Integrating feedback and reflection in teacher preparation," ELT Journal, vol. 62, no. 1, pp. 37-46, 2008.

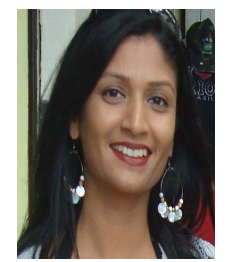

Rashika Sharma was born in Suva, Fiji. Rashika obtained her Masters in Education degree from Auckland based Unitec Institute of Technology in 2010. She also holds a Postgraduate Diploma and a Bachelors degree in Environmental Sciences from University of the South Pacific, Suva, Fiji. Rashika is currently the curriculum leader and lecturer in the department of Integrated Practice at Unitec Institute of Technology specialising in sustainable practice, societal context and generic skills on the Bachelor of Applied Technology. Rashika's research focus is on education for sustainability and takes keen interest in student centered teaching and learning strategies.

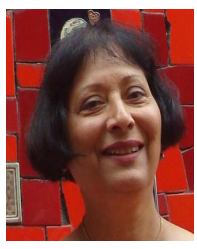

Sylila Monteiro teaches a wide range of communication and integrated practice papers across Unitec Institute of Technology including, critical thinking and sustainability. She previously taught at Zambia Institute of Technology in Zambia. She specialises in business document translation services for French and Portuguese organizations engaged in international communication. She also provides training for NZ Army personnel in Portuguese and French as preparation for overseas assignments. Her consultancy work involves Industry Training in Communication on Management Development Programmes. Sylila's research interests include interdisciplinary integrated practice in education, intercultural communication and sustainability. She has presented her research at several conferences in New Zealand and overseas. 